\title{
Acreditación de los programas de formación de especialistas médicos. Declaración de la Academia Chilena de Medicina
}

\author{
Accreditation of medical specialties programs in Chile. \\ Position paper by the Chilean Academy of Medicine
}

\author{
Este documento oficial de la Academia Chilena de Medicina \\ será reproducido en distintas revistas médicas
}

E 1 Poder Legislativo está deliberando sobre una eventual reforma a la ley de Aseguramiento a la Calidad de los Programas en la educación superior. La Academia Chilena de Medicina estima que una reforma o proyecto de Ley sobre el aseguramiento de la calidad de los programas de formación de especialistas médicos debe garantizar resguardos claros de la independencia de las entidades certificadoras respecto de las autoridades políticas, universitarias o de los prestadores de salud. La Academia piensa que las necesidades de especialistas del país deben ser abordadas con planes que no reduzcan los estándares formativos de los programas, respetando la diversidad y la pluralidad de las instituciones, intentando lograr siempre una atención de calidad asegurada.

La formación universitaria programada de especialistas médicos en Chile se inició hace 60 años y, la acreditación de los Centros Formadores, comenzó en 1980, por iniciativa de la Asociación Chilena de Facultades de Medicina (ASOFA$\mathrm{MECH}$ ). Desde ese año, se cauteló celosamente las condiciones básicas de los programas y centros asistenciales en los que ellos se desarrollaban. Este proceso, pionero en la educación superior del país, fue de considerable beneficio para nuestra medicina al introducir requisitos de calidad en esta formación de postítulo y contener, dentro de lo posible, defectos del proceso formativo de especialistas. Desgraciadamente, en la última década, estos defectos se fueron reiterando y agravando. Nos preocupan especialmente la existencia de programas no acreditados o de jornada parcial, a veces insuficientes en recursos, desarrollados en centros formadores inadecuados o bajo la responsabilidad de personas sin entrenamiento en docencia; aceptación de un número excesivo de Residentes en relación a la capacidad de los centros formadores; exigencia a los médicos en formación de realizar labores asistenciales para compensar las carencias de personal de los establecimientos de salud, distrayéndolos de su objetivo formativo; exigencias de matrículas y aranceles induciendo a estos médicos a emplearse en trabajos paralelos a sus programas para poder financiarlos.

El año 2006, la ley 20.129 sobre "Aseguramiento de la calidad de la Educación Superior" y la creación de la Comisión Nacional de Acreditación, ofrecieron a la educación médica de postítulo y, en particular, a los programas de especialización médica, la oportunidad de mejorar su calidad, corrigiendo gradualmente algunos de estos problemas. Adaptándose a la ley, el Colegio Médico de Chile, la Asociación Chilena de Facultades de Medicina, la Asociación de Sociedades Científicas de Chile y la Academia de Medicina del Instituto de Chile -que son las principales instituciones médicas del país- formaron conjuntamente en abril de 2008 la "Agencia Acreditadora de Programas y Centros Formadores de Especialistas Médicos" (APICE), entidad privada y sin fines de lucro, destinada al control y desarrollo de la formación universitaria de especialistas. APICE obtuvo personalidad jurídica en 2008 y en enero de 2009 fue autorizada por la Comisión Nacional de Acreditación (CNA) para acreditar los programas del post-título médico en Chile.

Aunque esta tarea resultó ser muy amplia, 
porque en el país 16 universidades ofrecen alrededor de 250 programas de formación en más de 60 especialidades médicas, en los casi cuatro años desde su creación APICE ha respondido satisfactoriamente a las solicitudes de acreditación, contando para ello con la colaboración de algo más de 270 profesionales con experiencia académica, clínica y administrativa, que se han desempeñado en el Directorio, los Consejos Acreditadores o como pares evaluadores. En efecto, la agencia ha logrado acreditar hasta ahora 46 programas, permitiendo a las Escuelas de Medicina cumplir tanto con la ley de "Aseguramiento de la Calidad de la Educación Superior" como con la de "Autoridad Sanitaria y Gestión" (ley 19.937), que le exige a los candidatos a especialistas haber realizado su formación en programas "debidamente acreditados" para ingresar al registro oficial de prestadores de la Superintendencia de Salud.

No obstante, a pesar del beneficio asociado a la acreditación oficial del post-título médico en Chile, la ley 20.129 sobre "Aseguramiento de la Calidad de la Educación Superior" y su brazo ejecutor, la Comisión Nacional de Acreditación (CNA), han sido cuestionados por diversos sectores, que estiman necesario reformar la organización y disposiciones reglamentarias que norman esta actividad. De hecho, el poder ejecutivo ya presentó un proyecto de modificación a esta Ley. Uno de los cuestionamientos a este proyecto de ley es que sólo exige a las universidades la acreditación de la educación médica de pre-grado, dejando como voluntaria la de los programas de post-título. Esto, además de desincentivar a las Facultades de Medicina a acreditar sus programas de post título, encierra el grave error de subestimar la responsabilidad en la práctica de la medicina especializada. La verdad es que cuanto mayor es la especialización mayor es la complejidad de la profesión, y la responsabilidad tiende a acrecentarse. El Estado debiera garantizar por igual la calidad de la formación médica del pre-grado y la del post-título, abordando la enseñanza de la medicina como un todo, porque en la práctica se trata de un proceso continuo. Además, las universidades formadoras deben asegurar la calidad de los programas de formación de los especialistas médicos. De otro modo, sus egresados no podrán ser especialistas (ley 19.937) y la población general quedará expuesta a variaciones significativas en la calidad del servicio. En el proyecto de ley que se tramita en el Parlamento no queda claro qué ocurrirá con las agencias acreditadoras que hasta ahora han cumplido con sus funciones ni con los programas que han sido acreditados por éstas. Este, como cualquier nuevo proyecto de reforma a la ley 20.129 de "Aseguramiento de la Calidad en Educación Superior", debe considerar y respetar el listado oficial de los programas de post-título médico que ya han sido acreditados, dando continuidad a un proceso de certificación que ha demostrado eficiencia, neutralidad y confiabilidad, logrando una mejora significativa en el aseguramiento de la calidad de la educación del post-título médico en Chile.

Santiago, 13 de junio de 2013 